EPiC Series in Engineering
Volume 3, 2018, Pages 1248-1251
HIC 2018. 13th International
Conference on Hydroinformatics

\title{
Meandering evolution and width variation, a physics-statistical based modeling approach
}

\author{
S. Lopez Dubon ${ }^{1}$, D. P. Viero ${ }^{1}$, and S. Lanzoni ${ }^{1}$ \\ Department of Civil, Environmental and Architectural Engineering, University of Padua, Italy \\ sergio.ldubon@dicea.unipd.it
}

\begin{abstract}
Many models have been proposed to simulate and understand the long-term evolution of meandering rivers. These models analyze the hydraulics of the in-channel flow and the river bank movement (erosion - accretion) process in different ways, but some gap still remain, e.g. the stability of long-term simulations when width variations are accounted for. Here we proposed a physics-statistical based approach to simulate the river bank evolution, that erosion and deposition processes act independently, with a specific shear stress threshold for each of them. In addition, we link the width evolution with a parametric probability distribution (PPD) based on a mean characteristic channel width. We are thus able to obtaining stable long-term simulations with realistic and reasonable spatio-temporal distribution of the along channel width.
\end{abstract}

\section{Introduction}

Meandering rivers are dynamic systems that migrate and evolve along floodplains as a consequence of complex interactions involving flow and sediment transport, channel geometry and floodplain topography [9]. During the last decades the study of meanders has fascinating many scientists, not just for their importance but also because of their complexity, allowing us to have a better understanding of meandering river dynamics, Nevertheless, many gaps still exist that need to be closed $[7,2]$. One of them is related to the stability of realistic long-term simulations when width variations are accounted for.

Commonly in long-term simulations of meander evolution, simplified models, derived through linearization and analysis of the relevant processes (e.g. [2]), are employes owing to their low computational cost. However, most of these models assume a constant channel width and a quite simplistic law for river bank movement. In this contribution we propose a mathematical model that consider channel width variations in solving the in-channel flow and a physics-based model for the river bank movements, corrected during the time and spatial evolution by means of a statistical model for controlling width variations.

G. La Loggia, G. Freni, V. Puleo and M. De Marchis (eds.), HIC 2018 (EPiC Series in Engineering, vol. 3), pp. $1248-1251$ 


\section{Hydraulic model}

The model adopted in this study describes the steady, spatially varying flow and the sediment transport in channels with arbitrarily varying channel axis curvature and channel width [6]. It is based on the two-dimensional shallow water equations for the flow field and the Exner sediment balance equation governing the bed dynamics. These equations are suitably linearized and solved by means of a two-parameter perturbation expansion technique, taking advantage of the fact that alluvial rivers often exhibit mild and long meander bends, as well as evident but relatively small width variations. The model, which accounts for the dynamic effects of secondary flows induced by both curvature and width variations, allows us to compute the in-channel flow field (i.e., water elevation, flow velocity and depth) and the equilibrium bed elevations corresponding to a given flow discharge.

\section{Bank erosion/accretion model}

We used a simple physics-based approach to mimic the river bank evolution, considering separately the erosion and accretion process that take place at the outer and inner banks, respectively. A shear stress threshold for each process is assumed, such that a certain overlap can occur between erosion and deposition.

\section{Statistical model}

The bank erosion/accretion modeling based on the exceeding of a critical threshold tends to become unstable for long term simulations, giving rise to local problems of widening or narrowing until unrealistic values. In addition, it results quite difficult to handle the system response to cutoffs $[3,5,4]$. To solve these problems, we implemented a statistical approach whereby the inner and outer bank movements are somehow related by controlling the channel width through a suitable probabilistic density function.

Based on field evidences, we observe that for a given river, the channel width probabilistic distribution can be described by the cumulative density function (CDF) of a general extreme value $(\mathrm{GEV})$ distribution.

This statistical approach has two main purposes. The first is to connect both banks, by favoring or restricting the bank retreat/aggradation in function of the CDF and the mean channel width. The second purpose is to ensure as a restrictive condition on the values that can be attained by the channel width, thus avoiding the attainment of unrealistic channel widths.

\section{Case study}

To test the model, we choose as a case study the Ucayali river. No relevant hydraulic structures and human interventions exist along the considered river reach, that can thus evolve freely throughout the alluvial floodplain. Using a 32 years long data series $\mathrm{f}$ the planimetric configurations of the Ucayali river available from RivMAP [8], we computed the GEV for all the years. The parameters of the GEV distribution generally change not only from year to year, but result 
Figure 1: a) Short term (10 years) and b) long-term (7000 years) simulations of the Ucayali river planform evolution accounting for along channel width variations. The color vertical bar indicates the year of simulation.

Figure 2: T(A) Channel width and slope are plotted versus time; (B) Channel width is plotted versus channel slope.

also to depend on the sampling distance at which the channel cross section width is measured.

In order to compare the different probability distributions (70 per year, for the 32 years) we implement the Bhattacharyya distance coefficient (BDC [1]) that measures the divergence between two distributions: a value 1 indicate a very good agreement, while 0 implies that the two PDF are totally different. WE are then able to objectively evaluate the similarity/difference among the PDFs by considering different sampling distances and different years.

Next, we apply our modeling framework to simulate the evolution of the Ucayali river planform. Figure 1 (a) shows the results of a 10 years simulation (in clear gray), starting from the initial observed configuration (gray), as well as the configuration actually observed after 10 years (black). It clearly appears that despite the model limitations (e.g., constant discharge, soil and floodplain homogeneity), the model is able to mimic in an acceptable way the river evolution. Also note that the largest discrepancy between the observed and the simulated planforms occurs in the correspondence of the sharpest bends, that are out of the range of applicability of the linearized flow field [6]).

Given the acceptable accuracy of the model, we proceeded to perform a long-term simulation. The results are shown in Figure 1 (B), recording the rivers movements for a 7,000 years long simulation. The river moves inside the entire meander belt from left to right, leaving behind several oxbow lakes. Interestingly, the simulation allows to monitor the behavior of the mean channel half width as a function of time and of the mean channel slope (Figure $2(\mathrm{~A})$ ).

The mean width values and the slope values turn out to be highly correlated.At any change in slope it corresponds a change in width with some time lag time. This behavior emerges also from Figure 2 B, showing the width-slope time trajectories: the width initially increases with the slope, reaches a maximum and then decline until a new cutoff event let the system to restart the width-slope trajectory cycle.

\section{Conclusions}

1. - We used a physics-based simplified method to mutually constrain bank erosion and accretion to restrict width variations within a meaningful range of values, based on field observations (i.e., associated with the statistical distribution of observed river width).

2. - The normalized distribution of channel widths remains almost the same along time and is best fitted by a General Extreme Value distribution; the major variations in this width distribution are observed just after cutoff events. 
3. - A physics-based numerical model, in which with erosion and accretion rates are constrained according to the observed width distribution, allows stable long-term simulations with realistic width values.

\section{References}

[1] A. Bhattacharyya. On a Measure of Divergence between Two Multinomial Populations, 1943.

[2] Manuel Bogoni, Mario Putti, and Stefano Lanzoni. Modelingmeandermorphodynamics over selfformed heterogeneous floodplains, 2017.

[3] Esther C. Eke. Numerical modeling of river migration incorporating erosional and depositional bank processes, 2013.

[4] Esther C. Eke, Matthew J. Czapiga, E. Viparelli, Yasuyuki Shimizu, J. Imran, T. Sun, G. Parker, and Eke et Al. Coevolution of width and sinuosity in meandering rivers, 2014.

[5] Esther C. Eke, Gary Parker, and Yasuyuki Shimizu. Numerical modeling of erosional and depositional bank processes in migrating river bends with self-formed width: Morphodynamics of bar push and bank pull, 2014.

[6] Alessandro Frascati and Stefano Lanzoni. A mathematical model for meandering rivers with varying width, 2013.

[7] İnci Güneralp, Jorge D. Abad, Guido Zolezzi, and Janet M. Hooke. Advances and challenges in meandering channels research, aug 2012.

[8] Jon Schwenk, Ankush Khandelwal, Mulu Fratkin, Vipin Kumar, and Efi Foufoula-Georgiou. High spatiotemporal resolution of river planform dynamics from Landsat: The RivMAP toolbox and results from the Ucayali River, 2017.

[9] Giovanni Seminara. Meanders, apr 2006. 